\title{
Autologous Priming of Cardiopulmonary Bypass in Adult Patients, Effect on Blood Transfusion, Hemodilution and its Effect on Body Systems
}

\author{
MAMDOOH EL SHARAWY, M.D.; NADER A. EL BOREY, M.D.; DINA M. OSMAN, M.Sc. and \\ AHMED M.A. BAKRY, M.D.
}

The Department of Cardiothoracic Surgery, Faculty of Medicine, Zagazig University

\begin{abstract}
Background: Development of many techniques conserve blood in cardiac surgery has been established, to avoid the side effects of homologous blood transfusion. One of these techniques is the Retrograde Autologous Priming (RAP); which is a blood conservation technique designed to decrease the severity of hemodilution during cardiopulmonary bypass and thus decreasing perioperative transfusions.
\end{abstract}

Aim of Study: The aim was to examine the safety and efficacy of RAP and its role in decreasing adverse outcomes on body systems after cardiac surgery.

Patients and Methods: This work was performed on 60 adult patients indicated for open heart surgery as valvular heart disease or coronary heart disease. 30 patients were operated using RAP technique and 30 patients using ordinary priming method of cardiopulmonary bypass (CPB).

Results: The CPB mean time was significantly shorter in the RAP group. The hemoglobin $(\mathrm{Hb})$ level and hematocrit (Hct) concentration in the perioperative and postoperative time as significantly higher in the RAP group also the platelet count was significantly higher in the RAP group $(p<0.05)$ with decreased incidence of post-operative bleeding in the RAP group. Also, there was significant reduction in the incidence of post-operative liver affection; there was no statistically significant difference in postoperative renal, pulmonary and neurological complications $(p>0.05)$ between the two groups.

Conclusions: RAP is an efficient and economical method in limiting the amount of priming volume of the CPB system, causing less hemodilution, reducing intra- and postoperative blood transfusion and decreasing adverse effects of hemodilution on body systems.

Key Words: Retrograde autologous priming - Autologous blood - Hemodilution - Platelet count - Liver Kidney - Pulmonary - Neurological complications.

Correspondence to: Dr. Mamdooh El Sharawy,

The Department of Cardiothoracic Surgery,

Faculty of Medicine, Zagazig University

\section{Introduction}

OPEN heart surgery is associated with increased demand for blood transfusion, many efforts have been done to decrease the number of blood units transfused to each patient [1]. Blood loss decreases the ability of cardiovascular system to maintain the systemic and myocardial oxygen demand thus increasing the risk of transmission of blood-borne infections [2]. Priming the pump with $1500 \mathrm{cc}$ of a balanced electrolyte solution, the patient is connected to the CPB machine. Reduction of the prime volume may thus be achieved by modification of the circuit [3]. The prime solution is displaced by autologous blood from the circuit and into a collection bag [4]. This study reporting the effectiveness of RAP and to assess the effect of RAP on reducing allogeneic packed red cell (RBC) transfusions and effect of hemodilution on different body systems in adult cardiac surgery.

\section{Patients and Methods}

A prospective, randomized, controlled study was performed in patients presented for primary coronary artery bypass grafting $(\mathrm{CABG})$, and valve replacement operation in Zagazig University Hospital from June 2012 to June 2013. The sample size was 60 adult patients they were randomized as 1 patient of every 5 patients in both groups to either the standard priming group which contained 30 patients (group B) or the retrograde autologous priming group (RAP) (group A) contained 30 patients.

Inclusion criteria included: Adult patients with valve heart disease or coronary heart disease.

Exclusion criteria were: Patients under 18 years or above 60 years old, patients with preoperative Hct below $30 \%$, emergency operations, redo- 
operations, patients on beating heart (CABG), patients with neurological deficit or stroke patients with cold crystalloid cardiology solutions and patients with intraoperative bleeding of surgical or medical cause.

Anesthetic and surgical management: Routine preoperative medications and induction of anesthesia were performed in the usual manner. Baseline Hct concentration was done before induction of anesthesia to determine the amount of fluid which will be removed from the CPB in the RAP group.

Management of $C P B$ : Ordinary priming solution with 500CC saline and 1000 ringer with 5000-unit heparin with 200CC mannitol.

\section{RAP Description:}

The CPB circuit consists of several components including: A membrane oxygenator with an isolated reservoir, centrifugal pumps, an arterial line filter and tygon tubing. The circuit is designed to accommodate the lowest priming volume. The CPB circuit is usually primed with $1000 \mathrm{cc}$ of ringer solution, $500 \mathrm{cc}$ of saline solution, 200 cc mannitol, and 5000 units of heparin. The volume remaining in the circuit is approximately $1.7 \mathrm{~L}$.

In order to introduce the retrograde autologous priming technique a one quarter-inch recirculation line is diverted off the arterial line into the venous reservoir. A side branch from the recirculation line is connected to a $\mathrm{Y}$ piece which leads to 1 liter prime bags. The collecting bags must be put in a position which is higher than the level of the heart thus preventing air entrance into the aorta. Autologous blood will replace the circuit's prime by alternating clamps applied at $\mathrm{A}, \mathrm{B}$, and $\mathrm{C}$, during stages of the RAP (Fig. 1).

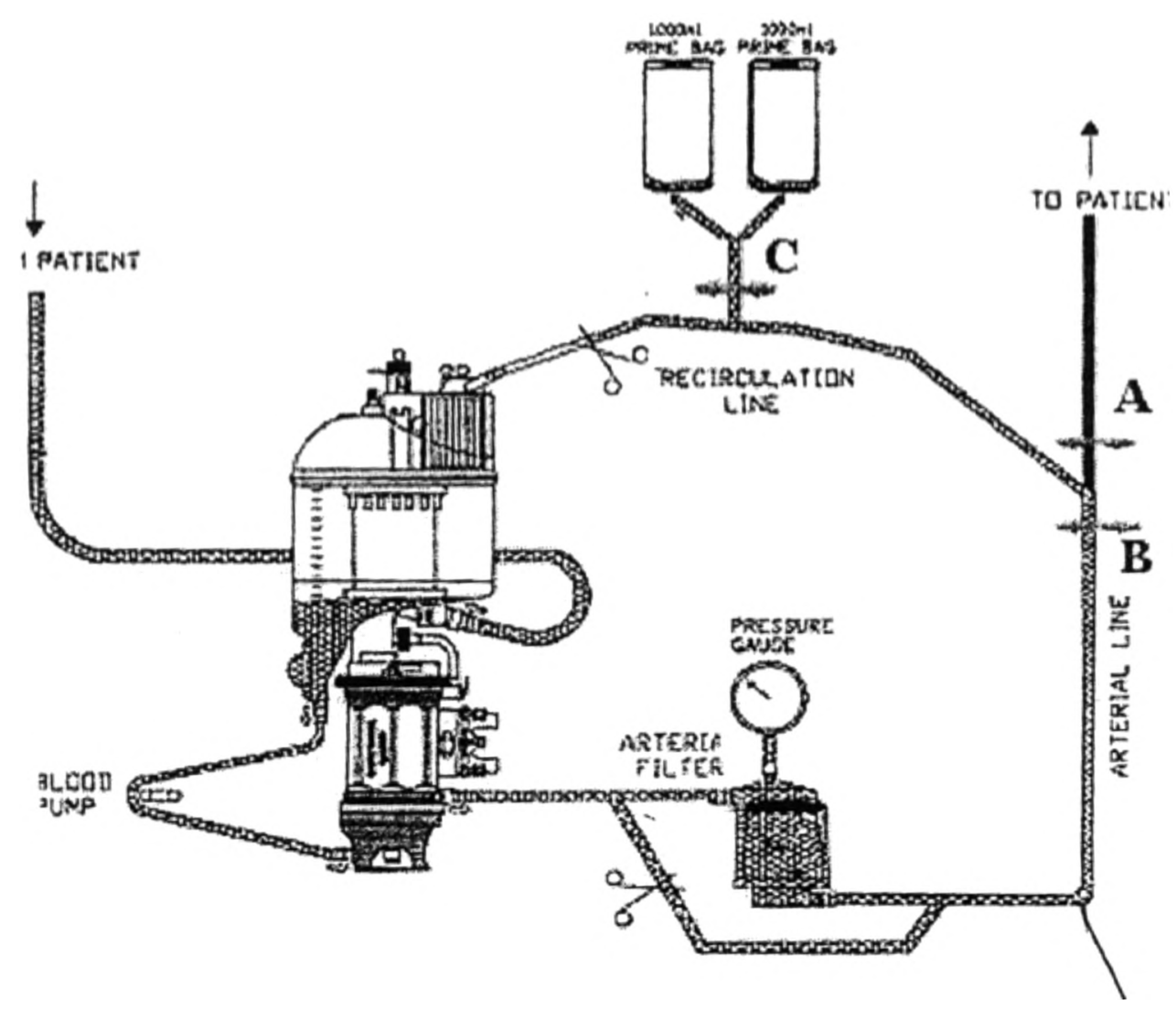

Fig. (1): Introducing RAP in the CPB.

Step 1: Aortic and venous cannulation are performed simultaneously with priming and recirculation of the cardiopulmonary bypass, then connected to their corresponding lines. Clamps are placed at A, B, and C, as shown in Fig. (1).

Step 2: Prime displacement from arterial line; partial removal of the clamp located at position C thus allowing blood to be directed retrograde from the patient's aorta to the aortic cannula thus to the arterial line. This will result in displacement of about $0.15 \mathrm{~L}$ of clear priming solution into the prime bag.

Step 3: Prime displacement from venous line; the clamp at position B is removed just after putting 
the clamp in position A, allowing the venous blood to drain from the patient. The arterial pump is rotated at a rate of 0.4 to 0.5 liters per minute, allowing a sufficient level in the venous reservoir. The line clamp is removed from position $\mathrm{A}$ and put on at position $\mathrm{C}$ after the venous blood has displaced the priming solution in the venous reservoir, membranous oxygenator and arterial filter.

Step 4: Going on the bypass; the venous line clamp is removed and full CPB is reached gradually. Cardiopulmonary bypass is done in the standard technique. If during the CPB fluids are needed, this can be obtained from the clear prime collected in the prime bags. After finishing the surgical procedure, rewarming and weaning from $\mathrm{CPB}$ is done. Removal of arterial and venous cannula is performed and giving the correct dose of protamine.

\section{Results}

In this study the age range from 20 to 60 years in both two groups with mean age $40 \pm 12$ in group and $41 \pm 13.5$ in group $B$, the females number was $11(36.7 \%)$ and number of males was $19(63.3 \%)$ in group A and number of females was 14 (46.7\%) and number of males was $16(53.3 \%)(p=0.43)$ in group B. There was no statistically significant difference between the two groups in age, gender, Preoperative parameters. Preoperative and postoperative results are comparable between the two groups as shown in Table (1).

Table (1): Pre-operative and Post-operative data of patients in both groups.

\begin{tabular}{|c|c|c|c|c|c|c|c|c|}
\hline & \multicolumn{2}{|c|}{ Pre-operative } & \multirow{3}{*}{$t$} & \multirow{3}{*}{$p$} & \multicolumn{2}{|c|}{ Post-operative } & \multirow{3}{*}{$t$} & \multirow{3}{*}{$p$} \\
\hline & $\begin{array}{c}\text { Group (A) } \\
(\text { no }=30)\end{array}$ & $\begin{array}{c}\text { Group (B) } \\
(\text { no=30) }\end{array}$ & & & $\begin{array}{c}\text { Group (A) } \\
(\text { no=30) }\end{array}$ & $\begin{array}{c}\text { Group (B) } \\
(\text { no=30) }\end{array}$ & & \\
\hline & Mean \pm SD & Mean \pm SD & & & Mean \pm SD & Mean \pm SD & & \\
\hline $\mathrm{Hb}$ & $13 \pm 1.8$ & $13.1 \pm 1.8$ & 0.202 & 0.841 & $11.9 \pm 1.9$ & $10.5 \pm 1.4$ & 3.126 & 0.003 \\
\hline Platelet & $272.2 \pm 52.1$ & $241 \pm 85$ & 1.713 & 0.092 & $219.8 \pm 41.7$ & $173 \pm 72.7$ & 3.057 & 0.003 \\
\hline Urea & $20.9 \pm 8.9$ & $17.8 \pm 5,6$ & 1.618 & 0.111 & $21.1 \pm 8.7$ & $17.8 \pm 5.6$ & 1.749 & 0.086 \\
\hline Creat & $1.1 \pm 0.5$ & $0.9 \pm 0.3$ & 1.33 & 0.189 & $1 \pm 0.3$ & $1.1 \pm 0.5$ & 1.593 & 0.117 \\
\hline SGOT & $71.6 \pm 47.4$ & $89.2 \pm 39.7$ & 1.555 & 0.125 & $71.6 \pm 47.4$ & $94.5 \pm 39.8$ & 2.027 & 0.047 \\
\hline SGPT & $41.3 \pm 16.3$ & $42.7 \pm 11.3$ & 0.15 & 0.698 & $41.3 \pm 16.3$ & $43 \pm 11.1$ & 1.638 & 0.11 \\
\hline
\end{tabular}

The preoperative data of the patients were more or less similar in both groups Mean HB level was $13 \pm 1.8 \mathrm{~g} / \mathrm{dl}$ in group A while it was $13.1 \pm 1.8 \mathrm{~g} / \mathrm{dl}$ in group B $(p=0.84)$. Platelet count mean value was 272.2 $\pm 52.1 \times 1000$ Lingroup A and 241 \pm $85 \times 1000 /$ in group B $(p=0.09)$ Mean urea level in group A was $20.9 \pm 8.9 \mathrm{mg} / \mathrm{dl}$ while in group B it was $17.8 \pm 5.6 \mathrm{mg} / \mathrm{dl}(p=0.111)$. Creatinine level mean value was $1.1 \pm 0.5 \mathrm{mg} / \mathrm{dl}$ in group $\mathrm{A}$ and $0.9 \pm 0.3$ in group $\mathrm{B}(p=0.189)$. SGOT level mean value was $71.6 \pm 47.4$ unit/L in group A89.2 \pm 39.7 unit/L in group $\mathrm{B}(p=0.125)$. SGPT mean value was 41.316 .3 unit/L in group $A$ and $42.71 \pm 11.3$ unit/L in group B ( $p=0.698)$. These data are similar because we tried to make the preoperative conditions of the two groups near to each other. The operations done for the two patients' groups are similar, 9 patients in the both groups had mitral valve replacement, 12 patients had coronary artery bypass grafts in both groups, 3 patients had aortic valve replacement in both groups and 6 patients in both groups had double valve replacement.

The mean cardiopulmonary bypass time was $81.5 \pm 7.6 \mathrm{~min}$ in the group A While in the group B it was $86.5 \pm 9.7 \mathrm{~min}$ which is statistically significant $(p=0.029)$. Mean cross clamp time in group A was $58.5 \pm 7.9 \mathrm{~min}$ and it was $62.5 \pm 8.6 \mathrm{~min}$ in group B $(p=0.065)$ with no statistical significance. The postoperative follow up of our patients has clinical aspect and laboratory aspect. the mean $\mathrm{HB}$ level in group A was $11.9 \pm 1.9 \mathrm{~g} / \mathrm{dl}$ and $10.4 \pm 1.4 \mathrm{~g} / \mathrm{dl}$ in group B ( $p=0.003)$ which is statistically significant. In our study platelet count mean level is $219.8 \pm 41.7$ $\mathrm{x} 1000 /$ gin group B $(p=0.003)$.

Post-operative renal function shows some kind of renal impermeant mean urea level was $17 \pm$ $0.8 \mathrm{mg} / \mathrm{dl}$ in group A and in group B it was $21.1 \pm$ $8.7 \mathrm{mg} / \mathrm{dl}(p=0.086)$ although it is statistically insignificant but it is better in the RAP group. Creatinine mean level was $1 \pm 0.3 \mathrm{mg} / \mathrm{dl}$ in group A and it was $1.1 \pm 0.5 \mathrm{mg} / \mathrm{dl}$ in group B. ALT rarely was increased in our study there was liver affection in both groups as both ALT and AST were increased but it was more in group B.

The mean value of the bleeding amount was $418.3 \pm 163 \mathrm{cc}$ in group A while it was $503.3 \pm 229 \mathrm{cc}$ in group B although there was no significant difference but the amount was more in the control group. In our study no pulmonary complications 
were detected in group A while I patient (3.3MJ $\%$ ) had chest infection, 1 patient $(3.3 \%)$ had hypoxia and patient (3-3\%) had atelectasis in group B. Also, no neurological complications were detected in group A in this study but 3 patients had irritability (10\%) in group B.

\section{Discussion}

The primary role of cardiopulmonary bypass (CPB) in cardiac surgery has been the maintenance of a bloodless and steady field. The cost of this comfort was mandatory busing of blood and its constituents which had further side effects. In addition to the transmission of infectious diseases and allergic reactions, the unwanted pulmonary and renal problems caused increased morbidity and mortality [5]. The decrease in the priming volume is followed by the lesser amount of hem dilution which decreases the transfusion requirements [6]. The aim of this study is to document the effects of retrograde autologous priming on transfusion requirements and perioperative outcomes.

Balachandran et al., in 2002, performed a study on patients presented for primary coronary artery bypass grafting (CABG). The sample size was 100 patients. There were significantly more female patients in the RAP group (13 of 51, 25.49\%) compared with the control group (4 of $49,8.16 \%$; $p=0.02$ ) [7]. Murphy et al., in 2006, studied 257 patients in the RAP group and 288 patients in the control group [8].

In the study of Hou et al., in 2009, it involved one hundred and twenty patients with mean age $35 \pm 15$ but it did not identify the number of males and females who did elective open heart surgery and were divided into the standard priming group and the RAP group. Homologous transfusion, hematocrit, and postoperative clinical outcomes were evaluated preoperatively [9].

Trapp et al., in 2015, who performed his study on 60 patients, 30 patient with RAP technique, and 30 patients with ordinary CPB [4]. There was a significant decrease in the $\mathrm{Hb}$ and $\mathrm{HCT}$ value once cardiopulmonary bypass began which could be explained by the significantly lower priming volume in the RAP group.

In our study the mean time of CPB was significantly less in the RAP (group A) compared to group B. Aortic cross-clamp time was also lesser in the RAP group without statistical significance.

Increased risk of bleeding has been associated with platelet deficiency, dysfunction or the effect of both. Platelet count was evaluated intra and post-operatively and factors contributing to platelet dysfunction were identified [10]. In our study platelet count showed significant difference between the two groups this shows that reduction of hemodilution improve the decrease in the platelet count so no patients in the RAP group A had significant bleeding, while only 1 case in the control group B had significant bleeding that required re exploration.

An association between the severity of hemodilution during $\mathrm{CPB}$ and perioperative acute renal failure has been assessed. Although previously reported, in our study, no statistical difference between the two groups regarding urea and creatinine levels were found which was similar to the results of Conlon et al., study [11]. The liver is highly susceptible to damage during CPB; several studies supported the fact that hemodilution which occurs during bypass affects tissue oxygenation and thus the liver [12]

In our study there was significant difference in the SGOT level between the two groups. no patients in the RAP group had significant bleeding. The risk of perioperative stroke was directly association with the degree of hemodilution. Prospective studies comparing different degrees of hemodilution during $\mathrm{CPB}$ are required to determine the nature of this association. In this study no patients showed CNS affection in the RAP group while $10 \%$ of patients had irritability in the ordinary $\mathrm{CPB}$ group also no pulmonary complications were detected in the RAP group.

\section{Conclusion:}

We conclude from this study that RAP is a simple, safe and economic technique to decrease the hemodilution and blood transfusion required in cardiopulmonary bypass for heart surgery.

\section{References}

1- BÉLISLE S. and HARDY J-F.: Hemorrhage and the use of blood products after adult cardiac operations: Myths and realities. Ann. Thorac. Surg., 62: 1908-191, 1996.

2- SPEISS B.S., GILLIES S.A., CHANDLER W., et al.: Changes in transfusion therapy and re-exploration rate after institution of a blood management program in cardiac surgical patients. J. Cardiothorac. Vasc. Anesth., 9: 168173, 1995.

3- BAR1S DURUKAN A., ALPER GÜRBÜZ H., et al.: Retrograde autologous priming in adult cardiac surgery: Effect on blood transfusion requirement. TGKD Cilt 17, Say, 1: 38-42, 2013.

4- TRAPP C., SCHILLER W., MELLERT F., et al.: Retrograde Autologous Priming as a Safe and Easy Method to Reduce Hemodilution and Transfusion Requirements 
during Cardiac surgery. Thorac. Cardiovascular Surgery, 6: 445-455, 2015.

5- KOCH C.G., LI L., DUNCAN A.L., et al.: Transfusion in coronary artery bypass grafting is associated with reduced long-term survival. Ann. Thorac. Surg., 81: 165057, 2006.

6- SEVERDIJA E.E., HEIJMANS J.H., THEUNISSEN M., et al.: Retrogradeautologous priming reduces transfusion requirements in coronary artery bypass surgery. Perfusion, 26: 315-21, 2011.

7- BALACHANDRAN S., CROSS M.H., KARTHIKEYAN S., et al.: Retrograde autologous priming of the CPB circuit reduces blood transfusion after coronary artery surgery. Ann. Thorac. Surg., 73: 1912-8, 2002.

8- MURPHY G.J. and ANGELINI G.D.: Indications for blood transfusion in cardiac surgery. Ann. Thorac. Surg., 82: 2323-34, 2006
9- HOU X1, YANG F., LIU R., et al.: Eur. J. Anesthesia, 2009 Dec retrograde autologous priming of cardiopulmonary bypass, 26 (12): 9-1901, 2009.

10- ROMLINI B.S., SÜDERLUNDI F., WAHLANDER H., et al.: Retrograde Autologous Priming as a Safe and Easy Method, to Reduce Hemodilution and Transfusion Requirements during Cardiac Surgery. (PMID:25803120). British Journal of Anaesthesia bja. Oxford journals.org ., 2014.

11- CONLON P.J., STAFFORD-SMITH M., WHITE W.D., et al.: Acute renal failure following cardiac surgery. Clinical journal of the American Society of Nephrology, 1: 19-32, 2006.

12- SHAHRBANO S., ASHKAN P. and MOHAMMAD ALI: Evaluation of Factors Influencing Liver Function Test in On-Pump Coronary Artery Bypass Graft Surgery, Iran J. Med. Sei., December, 38 (4): 308-313, 2013.

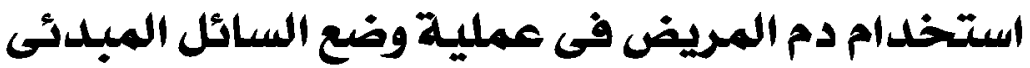

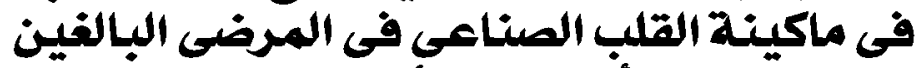

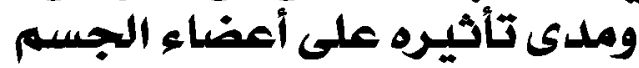

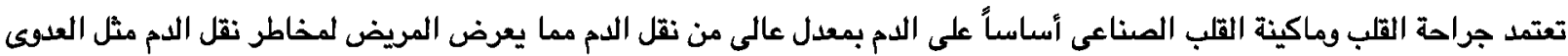

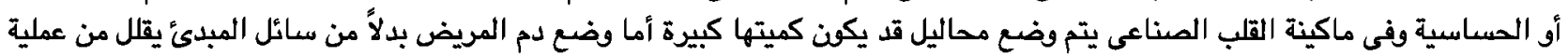

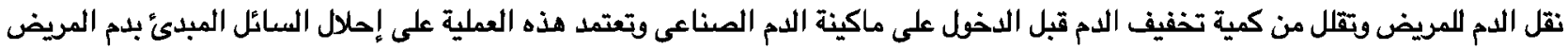

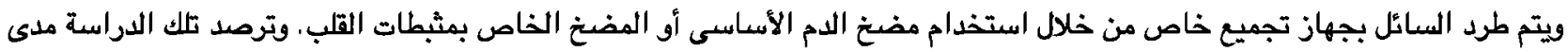

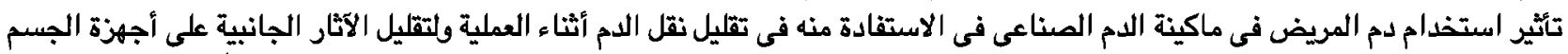

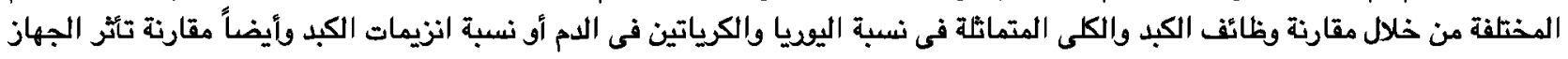

$$
\text { العصبى والريتين بين من المرضى الذين يخضعون اللداسة. }
$$

أهداف الدراسة: الهدف من هذه الدراسة هو تقليل ومقارنة النتائج الأولية لاستخدام دم المريض فى عملية وضع السائل المبئي فى ماكينة

$$
\text { القلب الصناعى. }
$$

لذا قمنا باختيار ـ7 مريضاً بطريقة عشوائية من المرضى المترددين على العيادة الخارجية بجامعة الزقازيق وتم تقسيمهم إلى مجموعتين

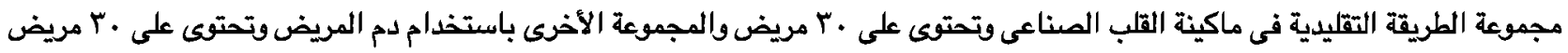
وتم مقارنة النتائج المعملية الهالية الإكلينيكية للمجموعتين.

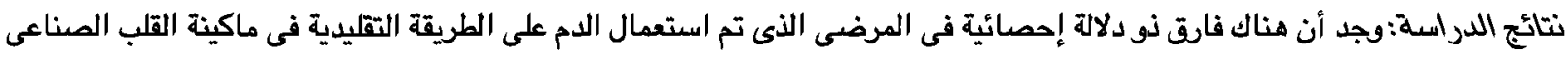
من حيث زيادة نسبة الهيموجلويين والصفائح الدموية ومن ثم إنخفاض الحالات الكات اللتس احتاجت تدخل جراحى نتيجة نزيف. كما وجد إنخفاض فى مضاعفات الكبد عن الطريقة التقليدية. الاستتاج: يعتبر استخدام الدم فى ماكينة القلب الصناعى طريقة أكثر أمناً وأقل تكلة وأقل مضاعفات من الطريقة التقليدية. 